\title{
Results of a Patient Survey Regarding COPD Knowledge, Treatment Experiences, and Practices With Inhalation Devices
}

\author{
Rajiv Dhand MD FAARC, Donald A Mahler MD, Brian W Carlin MD FAARC, \\ Nicola A Hanania MD MSc, Jill A Ohar MD, Victor Pinto-Plata MD MSc, Tina Shah MD MPH, \\ David Eubanks EdD RRT, and Sidney S Braman MD
}

\begin{abstract}
BACKGROUND: Successful inhalation therapy depends on the ability of patients with COPD to properly use devices. We explored subjects' COPD knowledge, including education they receive from health care providers, treatment experiences, and practices with inhalation devices. METHODS: A multiple-choice online survey, developed by a steering committee of American Thoracic Society clinicians and scientists, was administered to subjects with COPD who were sourced from the Harris Poll Online panel. RESULTS: Of the 254 respondents (mean age $61.8 \mathrm{y} ; 49 \%$ males), most subjects $(\mathbf{8 2} \%)$ claimed to understand their disease and available treatments, yet COPD symptoms and causes were well known to only $45 \%$ and $44 \%$ of subjects, respectively. Forty-three percent of subjects had ever used a pressurized metered-dose inhaler or dry-powder inhaler. Of the $54 \%$ of subjects who had ever used a small-volume nebulizer (SVN), $63 \%$ considered this device to be easy to use, $55 \%$ considered it to be fast-acting, $53 \%$ considered it to be convenient, and $38 \%$ considered it to be essential for treatment. Among subjects who had ever used them, SVNs were preferred by $\mathbf{5 4 \%}$ over other devices. One third of subjects desired more extensive education during office visits; $25 \%$ felt the time was insufficient to cover questions, and $15 \%$ felt their concerns about COPD treatment(s) were ignored. Subjects believed physicians $(32 \%)$, nurses $(26 \%)$, and no single provider $(\mathbf{2 8 \%})$ were primarily responsible for training and assessing proper inhalation technique. CONCLUSION: The survey showed differences between patients' beliefs and knowledge of COPD; the need for continuous education from health care providers, particularly on inhalation devices; and extensive use of pressurized metered-dose inhalers and dry-powder inhalers despite positive perceptions of SVNs. Key words: COPD; small-volume nebulizers; inhalation therapy. [Respir Care 2018;63(7):833-839. @ 2018 Daedalus Enterprises]
\end{abstract}

\section{Introduction}

In patients with COPD, inhaled medications reduce symptoms, decrease the frequency of exacerbations, and improve exercise tolerance and health status. ${ }^{1}$ A variety of delivery devices are available for administration of inhaled medications, including pressurized metered-dose inhalers (pMDIs), dry-powder inhalers (DPIs), and small-volume nebulizers (SVNs). ${ }^{2,3}$

\footnotetext{
Supplementary material related to this paper is available at http:// www.rcjournal.com.

Dr Braman presented a version of this article at the American Thoracic Society International Conference held May 13-18, 2016, in San Francisco, California.

Dr Dhand discloses relationships with Astra-Zeneca, Bayer, Cipla (India), GlaxoSmithKline, and Sunovion. Dr Mahler discloses relationships with Mylan Specialty, Boehringer Ingelheim, GlaxoSmithKline, Novartis,
} 
Evidence-based guidance, such as the Global Initiative for Chronic Obstructive Lung Disease (GOLD) strategy, advises that the recommendation of an inhaler device should

See the Related Editorial on Page 934

be based on drug availability, cost, the preference of the prescribing physician, and the skills and abilities of the patient. ${ }^{1}$ While these recommendations address the factors governing the choice of aerosol delivery devices from a medical viewpoint, the psycho-social dimensions of this choice have not been adequately explored, even in recent surveys that included subjects perspectives on COPD., ${ }^{4,5}$

The success of inhalation therapy is critically dependent on the patients' ability to follow instructions on how to use the device and to adhere to the regimen prescribed by their physicians. An inability to use hand-held inhalers is a major limitation of their use, especially in elderly patients with COPD. ${ }^{6-8}$ Surprisingly, although patients with COPD typically have persistent symptoms, in one study only $52 \%$ of subjects actually used the COPD medication prescribed to them, and 30-d and 90-d adherence was only $60 \%$ and $30 \%$, respectively. ${ }^{9}$ Patients may not adhere to therapy if symptoms are not adequately managed due to poor technique, language barriers, or inadequate instruction of inhaler use. ${ }^{10,11}$ Adherence may also be negatively affected by patients' attitudes and beliefs about their condition and their ability to adequately manage COPD (eg, concerns about efficacy, becoming dependent on inhalers, or fear of adverse effects). ${ }^{8} 12$ Suboptimal patient-physician interactions during office visits may also contribute to inhaler misuse or poor adherence. Patients may overestimate how well informed they are about their COPD. ${ }^{13}$ Important differences have been noted between the education imparted by health care providers and patients' understanding of key instructions and assessments. ${ }^{14}$ More importantly, physicians themselves, including pulmonologists,

\footnotetext{
Theravance, AstraZeneca UK, Sunovion, and Mayne Pharma. Dr Carlin discloses relationships with Sunovion, Boehringer-Ingelheim, Philips Respironics, Novartis, and Nonin. Dr Hanania discloses relationships with Novartis, Boehringer Ingelheim, GlaxoSmithKline, AstraZeneca, Roche, Teva, Sanofi/Regeneron, Cheisi, and Genentech. Dr Ohar discloses relationships with AstraZeneca, Novartis, Sunovion, Mylan, and Theravance. Dr Pinto-Plata discloses relationships with AstraZeneca, GlaxoSmithKline, and Mylan. Dr Shah and Mr Eubanks have no relationships to disclose. Dr Braman discloses relationships with Mayne Pharma, Covidien, Novartis, Genentech, and AstraZeneca.
}

Correspondence: Rajiv Dhand MD, University of Tennessee Graduate School of Medicine, 1924 Alcoa Highway, U-114. Knoxville, TN 37920. E-mail: rdhand@utmck.edu.

DOI: $10.4187 /$ respcare. 05715

\section{QUICK LOOK}

\section{Current knowledge}

Inhaled medications for the management of COPD reduce symptoms, decrease the frequency of exacerbations, and improve exercise tolerance and health status in patients with COPD. Successful inhalation therapy depends on the patient's ability to follow instructions and to use devices properly. Little research has been done to assess patient understanding of inhaled medications and the choice of delivery device.

\section{What this paper contributes to our knowledge}

Most subjects claimed to understand their disease and available treatments, but less than half actually understood the symptoms and causes of COPD. Many subjects reported that small-volume nebulizers (SVNs) were easy to use, fast-acting, convenient, and essential for treatment. Among subjects who had used them, SVNs were preferred by a majority over pressurized metered-dose inhalers and dry-powder inhalers. There was discordance between subjects' knowledge of COPD; the need for continuous education by health care providers, particularly on inhalation devices; and extensive use of pressurized metered-dose inhalers and dry-powder inhalers despite positive perceptions of SVNs.

may need additional education, especially related to advising subjects on aerosol delivery devices. ${ }^{15}$

These limitations render COPD management less effective than hoped or possible. ${ }^{10,14,16}$ Accordingly, we conducted an online survey among subjects with COPD with the objective of exploring their knowledge; their treatment experiences and practices, including the use of aerosol delivery devices, with special emphasis on small-volume nebulizers; and the education they received on these topics from their health care providers.

\section{Methods}

This survey of subjects with COPD was developed by a steering committee comprised of 9 American Thoracic Society clinicians and scientists (ie, the authors). This survey was submitted to the University of Tennessee Institutional Review Board and was determined to be exempt according to 45 CFR 46.101(b)(2). ${ }^{17}$

The fielding dates were between March 28 and April 7, 2016. All subjects were sourced to this open survey from the Harris Poll Online panel, a voluntary, anonymized, secure survey site that prevented duplicate entries. Harris Poll On- 


\section{Patient Survey of COPD Knowledge and Beliefs}

line members represent subjects with broad demographic attributes throughout the United States. Subjects were not preidentified or otherwise selected to participate in the survey.

Harris Poll Online volunteers were screened and enrolled into the survey if they reported that they were living in the United States, were at least 40 years age, and were diagnosed with COPD, chronic bronchitis, or emphysema by a health care professional. No other entry criteria for these COPD subjects were required. Enrolled subjects were reminded that identities were not disclosed and all responses remained strictly confidential. All data are reported for groups and not for individuals.

This open survey was comprised of multiple-choice questions (see the supplementary materials at http://www. rcjournal.com). Steering committee members achieved consensus on the content, wording, and formatting of each question. For overall readability, the Flesch-Kincaid Grade Level and Flesch Reading Ease were estimated to be 9.2 and 54.4, respectively (calculated with Microsoft Word 2013).

A total of 34 questions explored patient demographics; general COPD knowledge, such as risk factors, symptoms, and diagnostics tests; experience with COPD, including office visits, exacerbations, emergency room visits, and hospitalizations; COPD treatment knowledge, including exacerbation prevention; medication options; and use and maintenance of inhalation devices. These questions were augmented by additional supporting questions that developed detailed responses within the 34 primary questions. Adaptive questioning was employed to reduce survey complexity. Questions generally assessing opinions had 4 responses (strongly disagree, somewhat disagree, somewhat agree, strongly agree). Questions assessing general knowledge level had 6 responses (not at all knowledgeable, not very knowledgeable, somewhat knowledgeable, knowledgeable, very knowledgeable, and extremely knowledgeable). Questions assessing specific knowledge had detailed multiple choice answers from which the respondent could select those that best reflected their personal experience. With the exception of screening and certain demographic questions, many of the knowledge, opinion, and experience questions were presented in randomized order to prevent bias. Non-response options such as not sure, not applicable, or decline to answer were included as potential responses. The survey was expected to be completed in 15-20 min.

A sample size of $>100$ respondents supported quantitative analysis. Only complete surveys were analyzed. Demographic data for gender, race, retirement status, and employment status are presented as percentages of the population. Data pertaining to age are presented as mean $\pm \mathrm{SD}$. Because subjects were self-selected rather than a probability sample, no estimates of sampling error are calculated for survey results. Results are presented in accordance with recommendations for reporting results of Web-based surveys. ${ }^{18}$

\section{Results}

The demographics of subjects are shown in Table 1. The mean \pm SD age of the 254 respondents with COPD was $61.8 \pm 11.2$ years, and $49 \%$ were male. The greatest percentage of participants were white $(90 \%)$ and between the ages of 50-59 and 60-69y, which represented 55\% of the total population. The mean \pm SD age of the subjects at the time of diagnosis of COPD was $51.8 \pm 14.6 \mathrm{y}$. The majority of subjects were retired. Equal proportions of subjects were either unemployed because of illness or disability or were currently working. Of those who were working, only $12 \%$ were full-time employees. Pulmonary function tests were administered to the majority of subjects $(84 \%) ; 11 \%$ of subjects were not administered pulmonary function tests, and 5\% reported that they were unsure. In the year prior to the survey, $17 \%$ of subjects had visited the emergency room at least once for an exacerbation, and $14 \%$ were admitted at least once to the hospital for an exacerbation. The mean number of hospitalizations were $0.3 \pm 0.86$ SD per year.

Subjects generally believed that they were knowledgeable about their COPD. The majority of subjects (82\%) claimed to understand their disease and the treatment options available to them, yet less than half of subjects stated that they knew the symptoms of COPD (45\%) or the causes of COPD (44\%). Many subjects claimed that they understand the risk factors associated with COPD. Cigarette smoking was recognized as a substantial risk factor by $93 \%$ of subjects, and $77 \%$ of subjects also recognized exposure to secondhand smoke as a risk factor. Furthermore, $74 \%$ and $72 \%$ of subjects recognized occupational exposure and indoor air pollution, respectively, including some who knew about wood stoves used for cooking or heating (44\%), as risk factors for COPD.

Fewer subjects appeared to be knowledgeable about the treatment of COPD and the management of risk factors. Only $35 \%$ of subjects were knowledgeable about the medications used to treat or manage COPD, and only $27 \%$ were aware of the importance of preventing their COPD symptoms (COPD exacerbation). The majority of subjects were using a pMDI or a DPI for maintenance therapy, and the same proportion used a pMDI for rescue (Fig. 1). Fewer subjects were using SVNs to administer rescue medication and even fewer for controller medications. However, the percentage of subjects currently using an SVN was only $15 \%$ lower than those using a pMDI or a DPI.

Of the subjects using SVN, the majority had a positive opinion of them. Subjects stated that they were easy to use (63\%), fast-acting (55\%), convenient (53\%), and essential for their treatment (38\%). In contrast, SVNs were described 
Table 1. Baseline Demographics

\begin{tabular}{|c|c|}
\hline Parameter & $\begin{array}{l}\text { Percent } \\
\text { of Subjects* }\end{array}$ \\
\hline Male & 49 \\
\hline Mean age, $\mathrm{y} \pm \mathrm{SD}$ & $61.8 \pm 11.2$ \\
\hline $40-49$ & 17 \\
\hline $50-59$ & 30 \\
\hline $60-69$ & 25 \\
\hline $70+$ & 28 \\
\hline \multicolumn{2}{|l|}{ Ethnicity } \\
\hline White & 90 \\
\hline African American & 5 \\
\hline Native American & 2 \\
\hline Other & 3 \\
\hline \multicolumn{2}{|l|}{ Employment status } \\
\hline Employed (full time, part-time, or self-employed) & 23 \\
\hline Unable to work due to disability or illness & 20 \\
\hline Retired & 44 \\
\hline Other not employed & 13 \\
\hline \multicolumn{2}{|l|}{ Co-morbidity } \\
\hline High blood pressure & 57 \\
\hline Depression & 31 \\
\hline Asthma & 31 \\
\hline Anxiety & 30 \\
\hline Severe acid reflux (heartburn) & 27 \\
\hline Diabetes (Type 1 or 2 ) & 26 \\
\hline Sleep apnea & 26 \\
\hline Osteoporosis & 14 \\
\hline Heart disease & 13 \\
\hline Stroke & 8 \\
\hline Lung cancer & 3 \\
\hline \multicolumn{2}{|l|}{ Pulmonary function test } \\
\hline Yes & 84 \\
\hline No & 11 \\
\hline Not sure & 5 \\
\hline \multicolumn{2}{|l|}{ Ability to perform everyday activities } \\
\hline $\begin{array}{l}\text { Not troubled by breathlessness except on strenuous } \\
\text { exercise }\end{array}$ & 19 \\
\hline $\begin{array}{l}\text { Short of breath when hurrying on level (flat) ground } \\
\text { or walking up a slight hill }\end{array}$ & 33 \\
\hline $\begin{array}{l}\text { Walk slower than most people on level (flat) ground, } \\
\text { stop after about a mile or stop after } 15 \text { min of } \\
\text { walking at my own pace }\end{array}$ & 22 \\
\hline $\begin{array}{l}\text { Stop for breath after walking about } 100 \text { yards or } \\
\text { after a few minutes on level (flat) ground }\end{array}$ & 24 \\
\hline $\begin{array}{l}\text { Too breathless to leave the house or breathless when } \\
\text { doing ordinary tasks, such as dressing or eating }\end{array}$ & 2 \\
\hline Mean exacerbations in the past year $\pm \mathrm{SD}$ & $0.5 \pm 1.25$ \\
\hline 0 & 72 \\
\hline 1 & 17 \\
\hline 2 & 6 \\
\hline $3+$ & 5 \\
\hline Mean admissions for COPD in the past year \pm SD & $0.3 \pm 0.86$ \\
\hline 0 & 83 \\
\hline 1 & 14 \\
\hline 2 & 1 \\
\hline $3+$ & 2 \\
\hline
\end{tabular}

as time-consuming (18\%), burdensome (9\%), complicated (4\%), or expensive (24\%) in the minority of subjects. Slightly more than half (54\%) of subjects with COPD

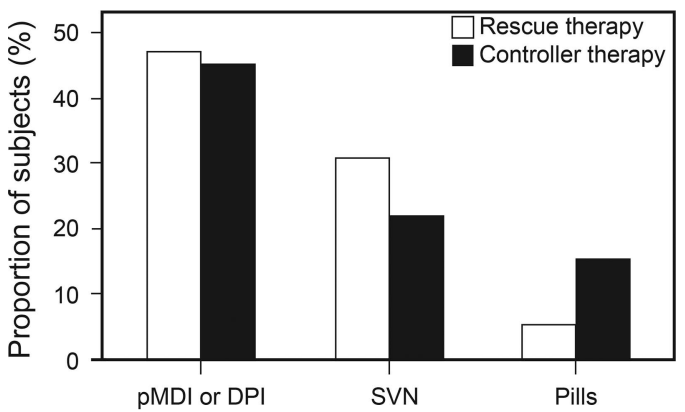

Fig. 1. Percentage of subjects currently using treatment and for what purpose. $\mathrm{pMDI}=$ pressurized metered-dose inhaler; $\mathrm{DPI}=$ dry-powder inhaler; SVN = small-volume nebulizer.

preferred using an SVN over a pMDI or a DPI. In contrast, $46 \%$ of subjects with COPD who had ever used or currently use a SVN disagreed.

About half of the subjects appeared to understand the use of their devices: $47 \%$ claimed they understood what the treatment devices are used for (inhalers and SVNs), and $52 \%$ claimed to know how to use the treatment devices (inhalers or nebulizers). Some of the respondents $(43 \%)$ understood how to clean and store the treatment device(s) (inhalers or nebulizers).

Office interactions and the sources of patient education were also evaluated in this survey. One third of respondents would prefer a more extensive interaction with their clinician during office visits pertaining to their medications, and one fourth of the respondents felt that there was not enough time during the appointment to cover all of their questions about COPD. A small but significant minority of subjects $(15 \%)$ felt that their health care provider often ignored their concerns about COPD treatment(s).

Subjects were surveyed about topics discussed during their first office visit (Fig. 2). Discussions pertaining to smoking cessation and treatment options were recalled by most subjects. Discussion about COPD management and prevention of risk were recalled by about $43 \%$ of subjects. Approximately $47 \%$ of subjects recalled being trained on how to use devices. Few subjects recalled a discussion about how to clean their devices. Nearly half of subjects responded that they were taught how to use a device on their first visit; $30 \%$ felt that the explanation was only periodically reinforced during subsequent office visits, while $30 \%$ were unsure that the conversation even occurred (Fig. 3). Only 7\% of subjects affirmed that the proper use of their treatment device was explained to them in more than half of the visits with their physicians, and 9\% stated that such a discussion occurred at each visit.

Subjects believed that various health care providers were responsible for assessing and training them on the proper use of inhalation devices. Physicians were thought to be primarily responsible for assessing proper technique and training by $32 \%$ of subjects. Nurses were believed to be 


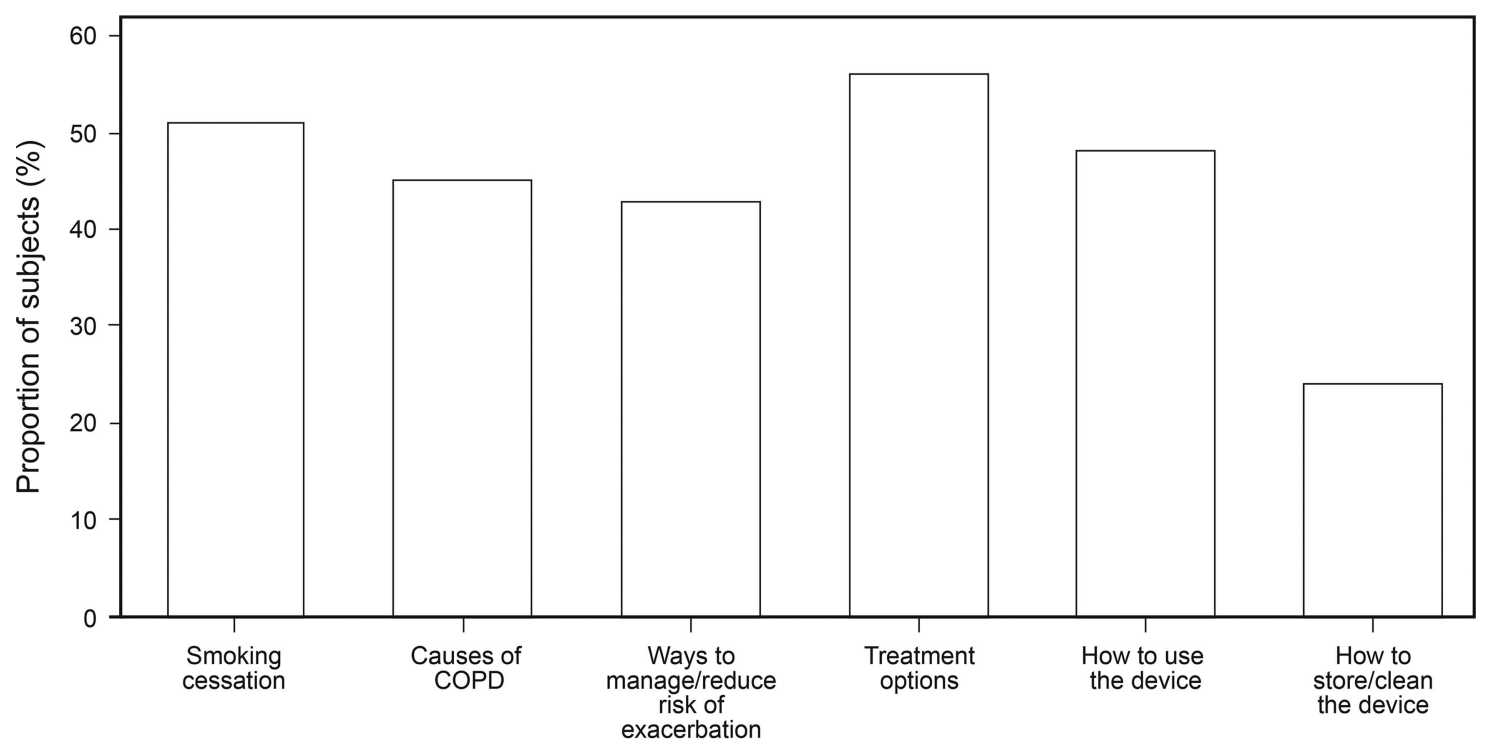

Fig. 2. Percentage of subjects stating what was discussed with them on their first office visit for COPD.

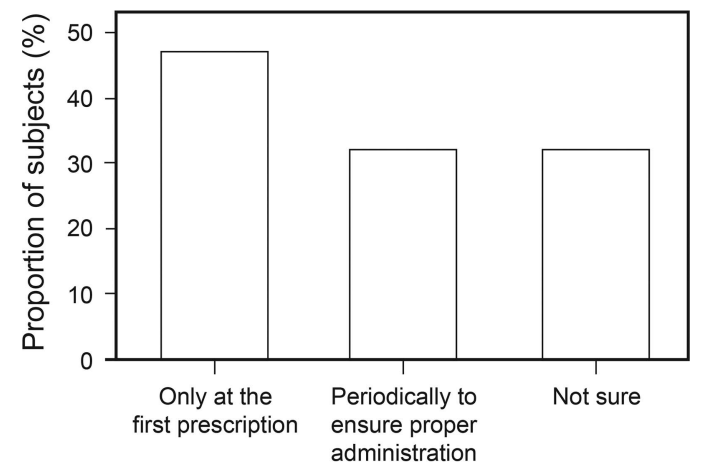

Fig. 3. Percentage of subjects stating how often inhaler technique and cleaning methods are assessed.

responsible by $26 \%$ of subjects, and $7 \%$ of subjects believed that pharmacists were responsible; $28 \%$ of subjects believed that no single provider was responsible for assessing technique and training on inhalation devices.

\section{Discussion}

This survey investigated COPD subjects' views and attitudes regarding their knowledge about COPD, treatment options, and device usage and maintenance. It also surveyed patient recollections of health care providers' instructions during office visits. It is comforting to note that the majority of COPD subjects were aware of their condition, its causative factors, and the relationship of COPD to tobacco smoking, exposure to secondhand smoke, and indoor air pollution. The survey, however, revealed significant differences between what subjects believed they knew and the actual information they possessed about
COPD management. The survey also shows the need for continuous patient education by health care providers. Subjects with COPD seek greater time with their health care providers during office visits. Furthermore, the survey found that COPD subjects had positive perceptions of nebulizers and their use.

The survey population is reflective of the COPD population; mostly white, equally split between male and female, 50-70 y of age, and with multiple comorbid conditions. ${ }^{1}$ While the majority of the subjects were retired, $>20 \%$ were unable to work because of their illness or disability, as seen in previous studies. ${ }^{13}$ Symptoms, especially shortness of breath, limited the activities of daily living in $55 \%$ of respondents. The frequency of exacerbations depends on several factors. ${ }^{18}$ In studies of subjects with COPD of at least 1-y duration, the annual rate of exacerbations varied from 0.5 to $3.5 /$ patient. ${ }^{19}$ In the Evaluation of COPD Longitudinally to Identify Predictive Surrogate End-points (ECLIPSE) study, which included only subjects with GOLD stage 2 to 4 COPD, the annual exacerbation rate varied from 0.85 to 3.0 between GOLD stages 2 and 4, respectively, and 19\% of subjects required hospitalization in the first year. ${ }^{20}$ In the Subpopulations and Intermediate Outcome Measures in COPD study (SPIROMICS) cohort, which included subjects with GOLD stage 1 to $4 \mathrm{COPD}$, the mean exacerbation rate in the year before enrollment was $0.4 \pm 0.87$, and the exacerbation rate in the first year of the study was $0.37 \pm 0.86 .{ }^{21}$ Only $7 \%$ of subjects had an exacerbation each year, and only $2 \%$ had 2 or more exacerbations in each year, whereas $51 \%$ did not experience an exacerbation in any year over $3 \mathrm{y} .{ }^{21}$ Therefore, the results of our study, which showed that $17 \%$ of subjects visited the emergency room at least once for an exacerbation 
and that $14 \%$ were admitted at least once to the hospital for an exacerbation in the previous year, are comparable to those reported in other cohorts that included patients across the spectrum of COPD severity.

Subjects' awareness and knowledge about causation of COPD, and its association with cigarette smoking, exposure to secondhand smoke, and indoor air pollution reflects the sustained efforts of health care providers and other public education programs. However, the survey reinforces the apparent disparity between how knowledgeable subjects state they are about COPD and the specifics of their knowledge. Prior studies have shown that less than half of subjects knew the symptoms of COPD or its causes, were aware of the medications available to treat COPD, and knew of COPD exacerbations or the importance of preventing them. ${ }^{13,22,23}$

Our survey demonstrates only a $15 \%$ difference between subjects who use pMDIs or DPIs compared with those who use SVNs. A previous survey of COPD subjects demonstrated the majority of subjects and their caregivers had a positive experience with SVNs, finding them easy to use, convenient, and fast-acting; they also believed that a nebulizer was better than only an inhaler and that using nebulizers improved their overall quality of life. ${ }^{24}$ Likewise, in our survey, SVNs were found to be easy to use, convenient, and fast-acting by most subjects. A minority of subjects had complaints about SVNs, with the most frequent, voiced by only $24 \%$ of subjects, being the cost. Surprisingly, more than half the subjects who had ever used or currently used an SVN preferred them over a pMDI or a DPI. This observation may be explained by the finding that only a minority of elderly COPD patients demonstrate successful use of pMDIs and DPIs. ${ }^{25}$ However, a companion survey to the one presented here demonstrated that the majority of U.S. pulmonologists surveyed do not routinely consider SVNs as an option for maintenance therapy in patients with COPD. ${ }^{15}$ Furthermore, only about half of surveyed U.S. pulmonologists reported discussing device options with their patients or screened for physical impairments that would impact delivery device choice, and only $16 \%$ screened for cognitive impairment. For optimal inhaled COPD therapy, the choice of the inhalation device needs to be matched to the patient's needs and preferences.

Approximately half of the study participants were comfortable with and understood the use of their devices, whether they used a DPI, a pMDI, or an SVN. They claimed to understand what the treatment devices were used for and how to use them. They also understood how to clean and maintain the devices. While approximately half of the subjects understand these concepts, it is concerning that the other half of the subjects surveyed are either not aware of or they are not following recommendations about the appropriate care and maintenance of their device. In ad- dition to the obvious risk of infection associated with inadequate cleaning of SVNs, ${ }^{26,27}$ nebulizers that are not cleaned after each use may begin to fail after only 40 uses with an antibiotic solution. ${ }^{28} \mathrm{~A}$ minority of U.S. pulmonologists reported being very knowledgeable in teaching patients how to use $(43 \%)$ or to clean/maintain (22\%) inhalation devices. While $70 \%$ reported discussing how to use aerosol delivery devices during patients' first visit, only $9 \%$ discussed how to clean and store them. ${ }^{15}$ These observations suggest more education, and reinforcement of that education, are warranted to ensure the best possible care for subjects.

The need for greater patient education is further supported when considering subjects who recalled discussing educational points during their first visit. Despite the known importance of smoking cessation, no more than half of the subjects recalled discussing smoking cessation at their first visit. Similar findings were noted in questions related to ways to manage or reduce the risk of COPD exacerbations. Approximately half of the subjects believed that inhalation device technique was discussed at the first visit, and even fewer subjects believed storage and cleaning of the device were discussed. Few subjects believed that these educational points were periodically discussed to ensure proper administration, although a substantial minority (30\%) recalled that such a discussion occurred. While such low figures may be biased by patient recall, education provided by out-patient health care providers may not adequately inform a proportion of patients who may subsequently be at greater risk of the consequences of COPD.

Limitations of this investigation include those related to online surveys. Patient selection was biased to those with sufficient skills, savvy, and resources to participate in such a survey. Many subjects without online access or sufficient skills to take such a survey may have been excluded, and their inclusion may yield different responses. Additional bias is likely included in this specific population as the survey was designed by consensus of the steering committee without formal validity and readability testing. The reading grade level was estimated to be 9.2 , presenting the possibility of increased error in how respondents interpreted the survey questions. The subjects' health care provider was not surveyed simultaneously. No independent confirmation of the diagnosis of COPD or its severity was documented, although most subjects reported they received a pulmonary function test and had significant effort-related shortness of breath. Additionally, the frequency of medication switches and replacement of SVNs were not addressed. Regardless, in this patient population, clear trends in COPD knowledge, attitudes, beliefs, and behaviors were elucidated, and important gaps in education were identified. Addressing these educational gaps can yield improved effective and comprehensive management for subjects with COPD. 


\section{Patient Survey of COPD Knowledge and Beliefs}

In summary, this online survey of subjects with COPD found that the majority were aware of their condition, its causative factors, and the relation to tobacco smoking, exposure to second-hand smoke, and indoor air pollution. The survey, however, revealed significant differences between what subjects believed they knew and the actual information they possessed about COPD management. The survey also showed the need for continuous patient education by health care providers. In addition, the survey found that, despite positive perceptions of nebulizer use, the majority of subjects with COPD continued to use pMDIs and DPIs for maintenance therapy, so more emphasis is needed on training subjects to use their aerosol delivery devices.

\section{REFERENCES}

1. Global Initiative for Chronic Obstructive Lung Disease (GOLD). Global Strategy for the Diagnosis, Management and Prevention of COPD. http://goldcopd.org. Accessed February 20, 2018.

2. Dolovich MB, Dhand R. Aerosol drug delivery: developments in device design and clinical use. Lancet 2011;377(9770):1032-1045.

3. Pirozynski M, Sosnowski TR. Inhalation devices: from basic science to practical use, innovative vs generic products. Expert Opin Drug Deliv 2016;13(11):1559-1571.

4. Hernandez P, Balter MS, Bourbeau J, Chan CK, Marciniuk DD, Walker SL. Canadian practice assessment in chronic obstructive pulmonary disease: respiratory specialist physician perception versus patient reality. Can Respir J 2013;20(2):97-105.

5. Menezes AM, Landis SH, Han MK, Muellerova H, Aisanov Z, van der Molen T, et al. Continuing to confront COPD international surveys: comparison of patient and physician perceptions about COPD risk and management. Int J Chron Obstruct Pulmon Dis 2015;10: 159-172.

6. Melani AS, Zanchetta D, Barbato N, Sestini P, Cinti C, Canessa PA, et al. Inhalation technique and variables associated with misuse of conventional metered dose inhalers and newer dry powder inhalers in experienced adults. Ann Allergy Asthma Immunol 2004;93:439446.

7. Melani AS, Bonavia M, Cilenti V, Cinti C, Lodi M, Martucci P, et al. Inhaler mishandling remains common in real life and is associated with reduced disease control. Respir Med 2011;105(6):930-938.

8. Restrepo RD, Alvarez MT, Wittnebel LD, Sorenson H, Wettstein R. Medication adherence issues in patients treated for COPD. Int J COPD 2008;3(3):371-384.

9. Jung E, Pickard AS, Salmon JW, Bartle B, Lee TA. Medication adherence and persistence in the last year of life in COPD patients. Respir Med 2009;103(4):525-534.

10. Rau JL. Practical problems with aerosol therapy in COPD. Respir Care 2006;51(2):158-172.

11. Georges CA, Bolton LB, Bennett C. Functional health literacy: an issue in African-American and other ethnic and racial communities. J Natl Black Nurses Assoc 2004;15(1):1-4.

12. Bourbeau J, Bartlett SJ. Patient adherence in COPD. Thorax 2008; 63(9):831-838.
13. Hernandez P, Blater M, Bourbeau J, Hodder R. Living with chronic obstructive pulmonary disease: A survey of patient's knowledge and attitudes. Respir Med 2009;103(7):1004-1012.

14. Moreo K, Greene L, Sapir T. Improving interprofessional and coproductive outcomes of care for patients with chronic obstructive pulmonary disease. BMJ Qual Improv Rep 2016;5:u210329.w4679. doi: 10.1136/bmjquality.u210329.w4679.

15. Braman SS, Carlin BW, Hanania NA, Mahler DA, Ohar JA, PintoPlata V, et al. Results of a pulmonologist survey regarding knowledge, attitudes and practices with inhalation devices for COPD. Respir Care 2018;63(7):840-848.

16. Han MK, Martinez CH, Au DH, Bourbeau J, Boyd CM, Branson R, et al. Meeting the challenge of COPD care delivery in the USA: a multiprovider perspective. Lancet 2016;4(6):473-526.

17. Code of Federal Regulations, Title 45, Part 46. Protection of human subject. https://www.hhs.gov/ohrp/regulations-and-policy/regulations/ 45-cfr-46/index.html. Accessed February 21, 2018.

18. Eysenbach G. Improving the quality of web surveys: the checklist for reporting results of internet e-surveys (CHERRIES). J Med Internet Res 2004;6(3):e34.

19. Seemungal TA, Hurst JR, Wedzicha JA. Exacerbation rate, health status and mortality in COPD-a review of potential interventions. Int J Chron Obstruct Pulmon Dis 2009;4:203-223.

20. Hurst JR, Vestbo J, Anzueto A, Locantore N, Müllerova H, TalSinger R, et al. Susceptibility to exacerbation in chronic obstructive pulmonary disease. N Engl J Med 2010;363(12):1128-1138.

21. Han MK, Quibrera PM, Carretta EE, Barr RG, Bleecker ER, Bowler $\mathrm{RP}$, et al. Frequency of exacerbations in patients with chronic obstructive pulmonary disease: an analysis of the SPIROMICS cohort. Respir Med 2017;5(8):619-626.

22. Kessler R, Ståhl E, Vogelmeier C, Haughney J, Trudeau E, Löfdahl CG, Partridge MR. Patient understanding, detection, and experience of COPD exacerbations. Chest 2006;130(1):133-142.

23. COPD Foundation. COPD Foundation releases groundbreaking COPE survey results: low patient awareness about COPD exacerbations poses barrier to effective management. http://www.copdfoundation.org/AboutUs/Press-Room/Press-Releases/ID/256/COPD-Foundation-ReleasesGroundbreaking-COPE-Survey-Results-Low-Patient-AwarenessAbout-COPD-Exacerbations-Poses-Barrier-to-EffectiveManagement.aspx. Accessed February 21, 2018.

24. Sharafkhaneh A, Wolf RA, Goodnight S, Hanania NA, Make BJ, Tashkin DP. Perceptions and attitudes toward the use of nebulized therapy for COPD: patient and caregiver perspectives. COPD 2013; 10(4):482-492.

25. Bellia V, Battaglia S, Matera MG, Cazzola M. The use of bronchodilators in the treatment of airway obstruction in elderly patients. Pulm Pharmacol Ther 2006;19(5):311-319.

26. Blau H, Mussaffi H, Mei Zehav M, Prais D, Livne M, Czitron BM, Cohen HA. Microbial contamination of nebulizers in the home treatment of cystic fibrosis. Child Care Health Dev 2007;33(4):491-495.

27. O'Malley CA. Device cleaning and infection control in aerosol therapy. Respir Care 2015;60(6):917-927.

28. Standaert TA, Morlin GL, Williams-Warren J, Joy P, Pepe MS, Weber A, Ramsey BW. Effects of repetitive use and cleaning techniques of disposable jet nebulizers on aerosol generation. Chest 1998(2):114:577-586.

This article is approved for Continuing Respiratory Care Education credit. For information and to obtain your CRCE

(free to AARC members) visit www.rcjournal.com

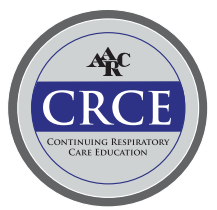

